\title{
EVALUATION OF STRUCTURE QUALITY OF WEB FROM ELECTROSPUN NANOFIBRES
}

\author{
Rimvydas Milašius, Jolanta Malašauskiené*
}

Kaunas University of Technology, Faculty of Mechanical Engineering and Design, Department of Materials Engineering, Lithuania, Studentu 56, LT-51424 Kaunas, *e-mail: jolanta.malasauskiene@ktu.edu

\begin{abstract}
:
Electrospinning is remarkably a simple and versatile method for producing nanofibres. The diameter of nanofibres can vary from $10 \mathrm{~nm}$ to $>1000 \mathrm{~nm}$. In electrospinning, most of the attention is focused on producing fibres with a uniform diameter. It is very important to understand how the diameter and its distribution vary with the materials used and the processing parameters. An analysis of literature sources has shown that the distribution curves of the diameters obtained are very complex and do not resemble normal distributions, while they do more closely correspond to those of compound distributions. The goal of this article is to analyse the distributions of the nanofibre diameters and to propose a new method for the evaluation process of nanofibres and the quality of a nanofibre web. The uniformity of structure and the quality of nanofibres web must be described by average values. The peaks of modal values and the percentage quantity of them must be used for evaluation of a web structure.
\end{abstract}

\section{Keywords:}

Electrospinning, quality, nanofibres, diameter, distribution

\section{Introduction}

A number of processing techniques such as drawing, template synthesis, phase separation, self-assembly, drawing, melt blowing and electrospinning, can be used to prepare nanofibres. Among them, electrospinning stands out as the most promising method for nanofibre production [1, 2]. Electrospinning is a process where fibres are created due to the electrostatic forces acting between two electrodes. This method has been known for more than 100 years, since the beginning of the 20th century, when John Francis Cooley filed the first patent for electrospinning in 1900. Further developments were made by William James Morton and John Zeleny. The latter published his work on the behaviour of fluid droplets at the end of metal capillaries. From 1931 to 1944 , Anton Formhals took out at least 22 patents on the theory of electrospinning. From literature sources, it is known that Nikolai Albertowich Fuchs, Igor' Vasil'evich Petryanov-Sokolov, Natalya D Rosenblum, also Sir Geoffrey Ingram Taylor, Darrell Reneker and others distinguished themselves in this area. During 1964-1969, Sir Geoffrey Ingram Taylor made a significant development in electrospinning and modelled the shape of the Taylor cone formed by a fluid droplet under the influence of an electric field [3-6]. Nevertheless, it was only at the end of 20th century that this method began to be used more widely after new technologies has been created and the ability to manufacture fibres on the nanoscale emerged. By electrospinning, it is possible to manufacture nanofibres from a polymer solution or melt on the scale of a few dozen to a few hundred nanometres [7]. The main advantage of a web from such nanofibres is the very high surface area of polymeric fibres, manufactured from a very small quantity of polymer having very high barrier properties - the pores of such a web can be smaller than those of red blood cells.

In the last two decades, a lot of papers have been published where the authors analysed the influence of various technological, ambient and polymer characteristics on the structure of a web [8-15]. Usually, most of the authors analysed the diameter of the nanofibres and used the average value of nanofibres for estimation from simply one or a few other SEM images. But, if we create an analysis of the nanofibre diameter distribution, we will find that in the majority of cases this distribution is not normal (Gaussian) [16-19]. Again, the distribution is more complex. Some of the authors state that the distribution of the nanofibre diameters could be described as a log-normal distribution, but such a method does not have a theoretical basis and also does not have a physical sense [2022]. It is well known that the values obtained are often described as having a log-normal distribution when a process depends on time, but the electrospinning process does not depend on the time, and this process continues throughout the entire time of manufacturing. Therefore, a log-normal distribution cannot be used for the estimation of diameter distribution.

In our previous works [23-25], we have analysed the various webs created from nanofibres and found variety of nanofibre diameter distributions. Because of this, it is impossible to compare the average values of nanofibre diameters. For such a comparison, according to the requirements of mathematical statistic, the distribution of the diameter must be the same, i.e. we can compare the values that are distributed in the same distribution - all in normal, all in log-normal or all in any other distribution, but all are the 
same. Since various authors obtained different distributions, it does not allow us the possibility to compare their results and to analyse all their results together. In our previous work on the estimation of diameter distribution, we proposed the utilisation of a normal compound type of distribution. Our research has shown the high precision of utilising the concept of compound distribution in obtaining an empirical result for the actual distribution.

The goal of this work is to propose a uniform method for the estimation of nanofibre web quality through the use of compound distribution and statistical characteristics for the entire process of web evaluation. This method provides a possibility to compare the different results obtained by various researchers and to characterise the nanofibre webs created by a uniform system of mathematical criteria.

\section{Theoretical}

It is well known that a compound distribution is a characteristic distribution for the evaluation of the structure of yarns that have been blended from several different fibres [26]. Let us analyse the distribution of a yarn that has been blended from three different kinds of fibres. For example, let us take a woollen yarn that consists of $50 \%$ fibre $A\left(d_{\text {average }}=16 \mu \mathrm{m}\right), 30 \%$ fibre $B$ $\left(d_{\text {average }}=18 \mu \mathrm{m}\right)$ and $20 \%$ fibre $\mathrm{C}\left(\mathrm{d}_{\text {average }}=20 \mu \mathrm{m}\right)$. Assume that the diameter distributions of all these three kinds of fibres are the same (see Fig. 1). In this case, the compound distribution of the blended yarn itself can be obtained from the following view (see Fig. 2).

When we compare the blended yarn diameter distribution with the majority of the distributions obtainedfor the diameters

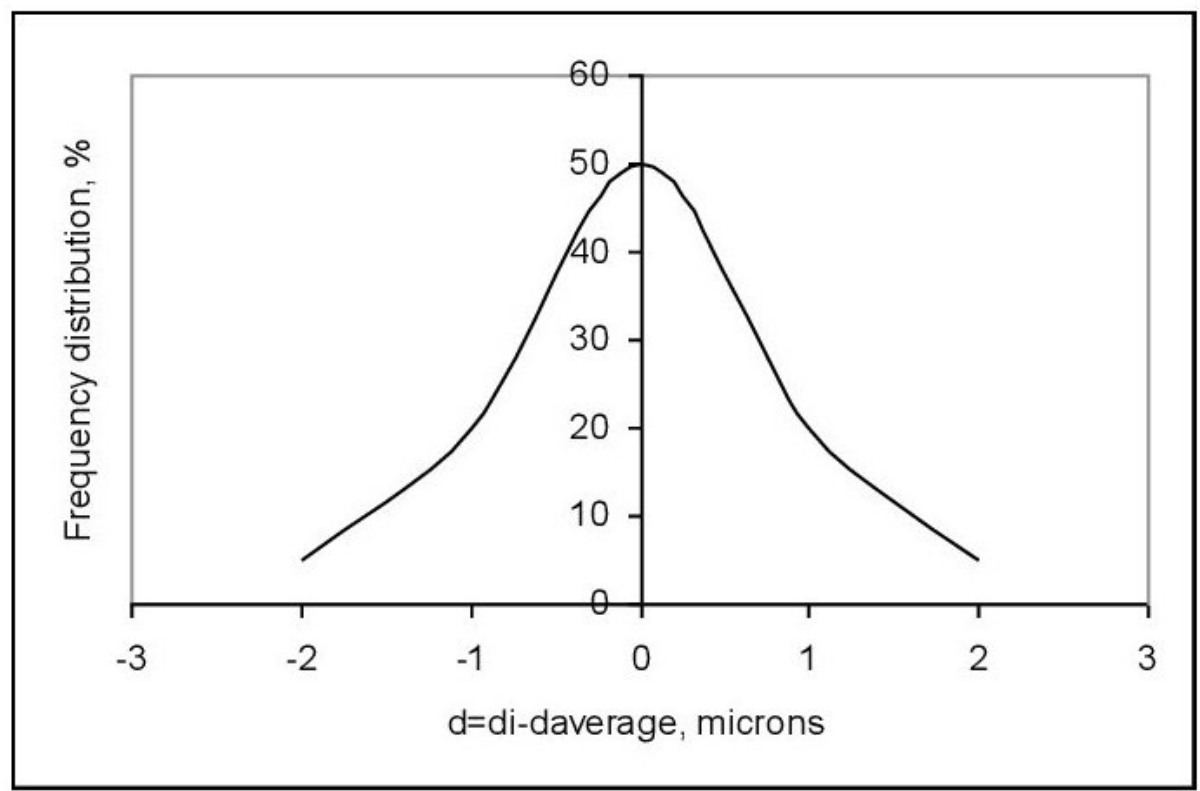

Figure 1. The distribution of the diameters of the blended yarn fibres.

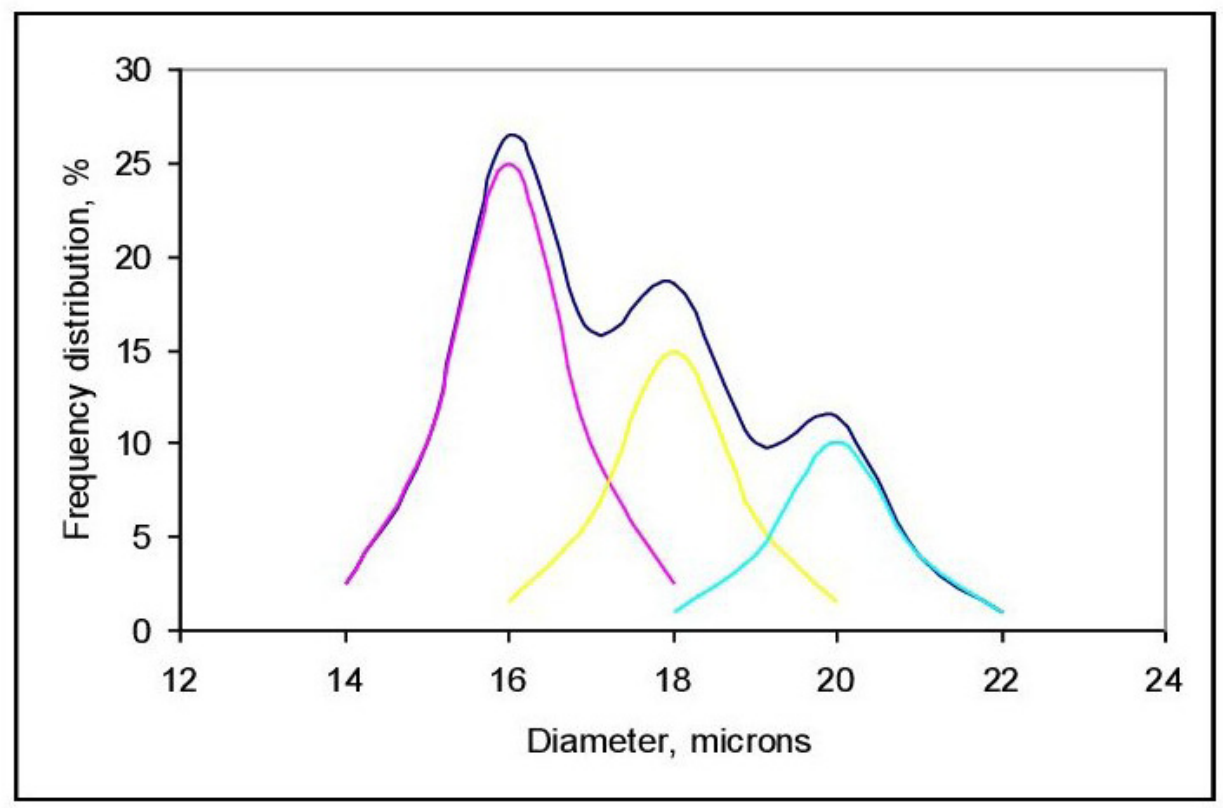

Figure 2. The compound distribution of the blended yarn fibre's diameter and the distributions of all the separate kinds of fibre diameters taken separately. 
of various electrospun nanofibres, we can see a very high similarity. Therefore, this means that the electrospun nanofibre diameter distribution can be described as a compound distribution consisting of several normal distributions together. Our previous works [23-25] have confirmed that a web of nanofibres can be formed from single and stick nanofibres. Stick nanofibres consists from two, three or more single nanofibres. The main problem is how to divide the single compound distribution into the single distributions of all the different kinds of fibres. In our previous work [23], the method of how to calculate compound distribution has been proposed, but this method is very complicated.

\section{Method of quality estimation}

In this work, we propose the short-cut method of dividing the compound distribution into several distributions. This method is much simpler than the method presented in our previous work [23] and is based on the modal value of each kind of fibre and on the assumption that each kind of fibre has its own normal distribution.

From Fig. 3, it is obvious that the empirical distribution of the nanofibre diameters has several peaks. The first peak is around $175-200 \mathrm{~nm}$, the second is around $275-300 \mathrm{~nm}$ and the third peak is around $400 \mathrm{~nm}$. According to the results, we can state that the diameter distribution consists of three normal distributions.

The first step of the short-cut method is to find the distribution of the first kind of nanofibres. The empirical values until the first modal value of distribution (175-200 nm) are set as the points of the left part of the first distribution. In this case, we considered that the first peak is the value where the diameter of nanofibres decreases no less than by two values. On the other side of the modal value, symmetrical points are marked, because it is considered that the diameter of each kind of nanofibres is distributed as it would be in a normal distribution.

The second step of this method is to establish the second distribution. Therefore, the left part of it is calculated as a difference between the empirical values and the values attributed to it by the first distribution (up until the second modal value, i.e. $275-300 \mathrm{~nm}$ ). The right part of the second distribution is found as in previous case, i.e. in the other side of the second modal value, the symmetrical points are marked. In the empirical curve, we can pick out the third peak and to make the same calculations, however, in the case presented here. But in our opinion, two first peaks are the most important, because the goal of electrospinning is to produce as thinner nanofibres as possible. The thicker nanofibres are defects and it is necessary to seek to avoid it. For this reason, it is proposed to estimate the quality of a nanofibres web by two first peaks. Lastly, by summarising the values of the two established distributions, a compound distribution can be calculated. According to the results presented in Fig. 3 , the $20 \%$ nanofibres is possible to attribute to the first distribution with modal value $187.5 \mathrm{~nm}$ and the $28 \%$ nanofibres is possible to attribute to the second distribution with modal value $287.5 \mathrm{~nm}$. If we achieve more nanofibres distributed by first distribution after some technological changes, it means that we change parameters of electrospinning in the right direction and less sticked nanofibres were formed.

In the next step of our investigations, we also check did such a method of dividing of distribution into few normal distributions is useful for other kinds of nanofibrous web. The empirical distribution with several peaks (Fig. 3) can be compared with histogram from a literature source [18] (see Fig. 4). In this figure, a histogram with two peaks was also found. According to the method presented above, let us analyse this histogram.

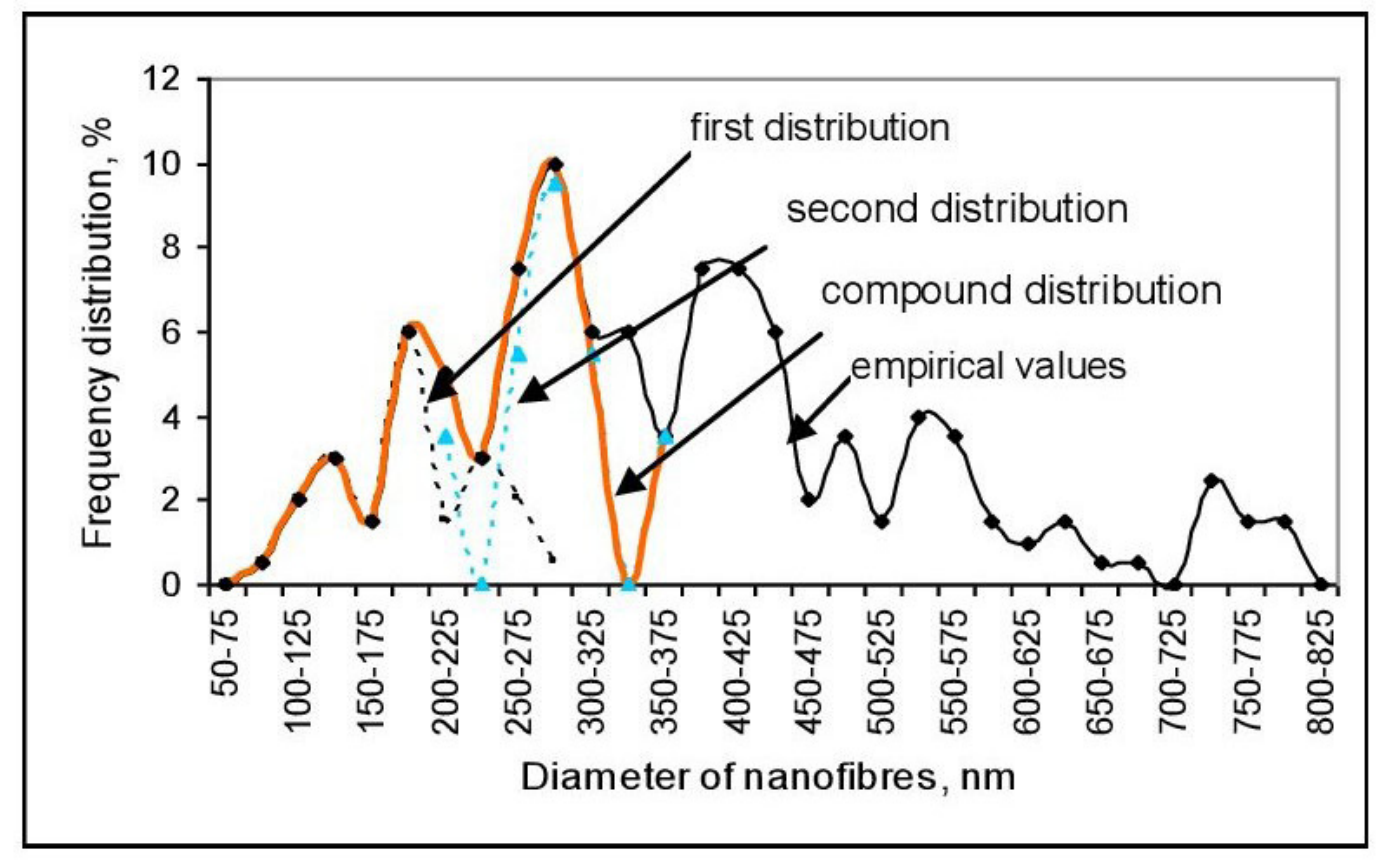

Figure 3. Compound distribution established by the short-cut method. 
From the histogram presented in Fig. 4, it is evident that the scale of probability is very small. For this reason, this distribution has been reworked by a summation of the two adjective values (instead of two intervals of $0.01 \mu \mathrm{m}$, we used interval $0.02 \mu \mathrm{m}$; see Fig. 5).

Now the probability is higher and this means that the accuracy of the method will be higher too. Increasing the intervals more than $0.02 \mu \mathrm{m}$ will have the negative aspect - it will create the problem to determine the peaks. Despite the reworking of the distribution, it is evident that in both histograms, few peaks can be noticed as well. According to this, we can state that the values of the PP diameter are not distributed according to normal distribution, but it is distributed according to compound distribution.

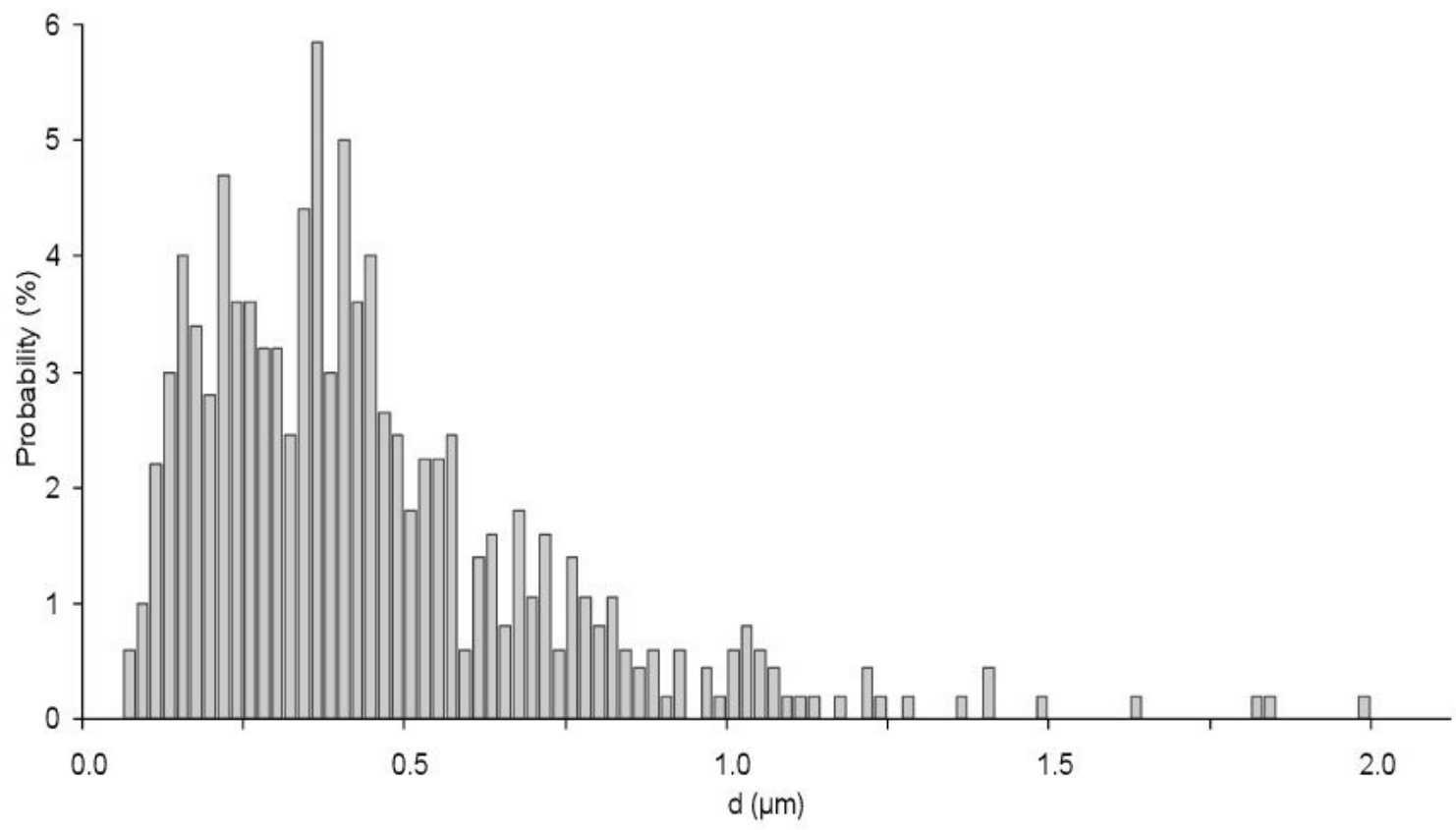

Figure 4. Fibre diameter distribution from PP [18].

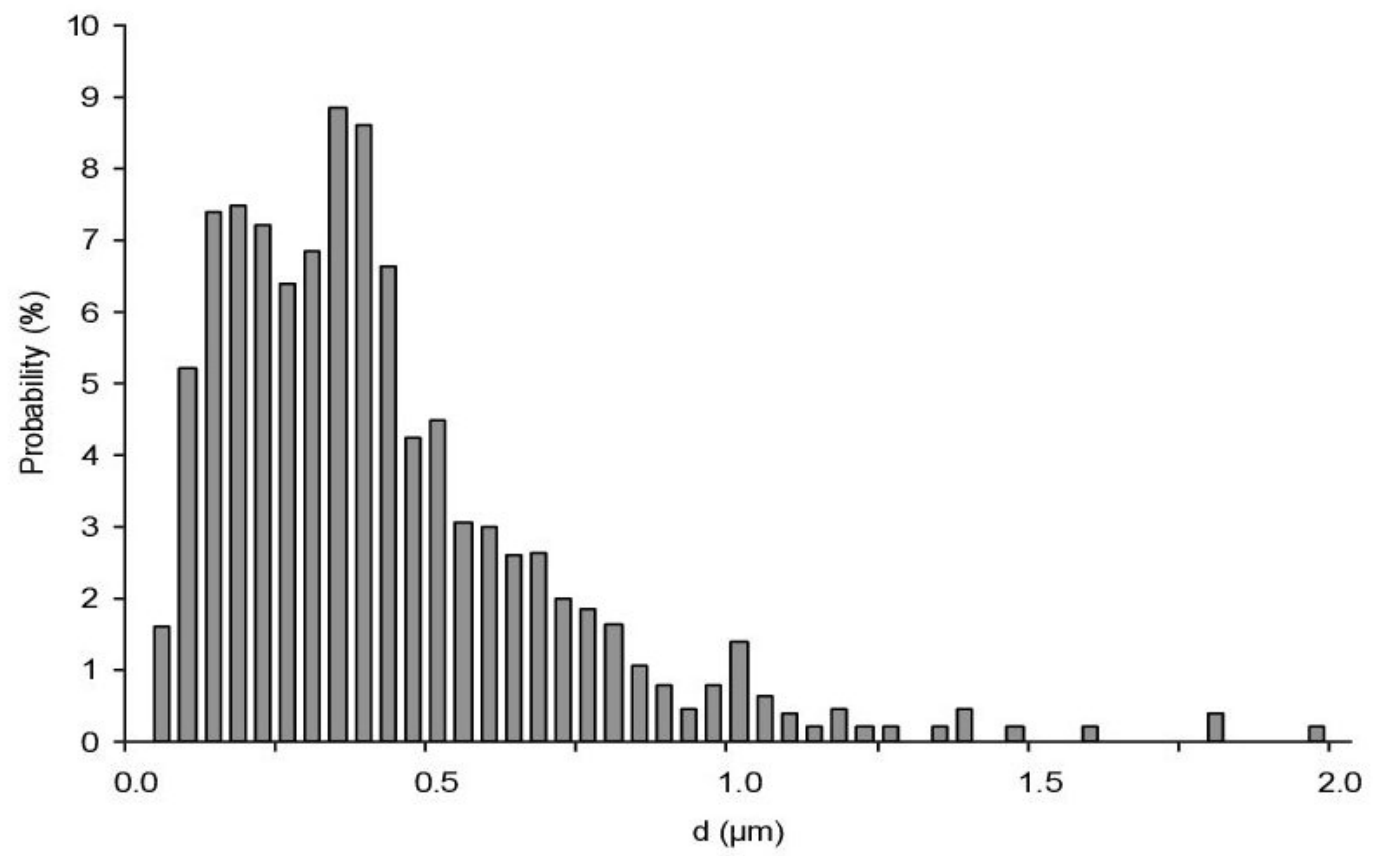

Figure 5. Reworked fibre diameter distribution from PP.

This means that this problem is typical for the electrospinning process regardless of the type of polymer used [18, 23-25]. For further analysis, the histogram from Fig. 5 will be used.

The first peak can be observed when the diameter of the nanofibres is around $0.2 \mu \mathrm{m}$ (in this case, it is assumed that the peak is the value where the diameter decreases by no less than two values). Hence, the left part of the first distribution was established according to empirical values until the first peak, while the right part of the first normal distribution was marked as a symmetrical set of points from the left side (see Fig. 6 (a)).

The second and total distributions were calculated as in the previous case (Fig. 6(b) and (c)). The second modal value in this histogram is $0.375 \mu \mathrm{m}$. 


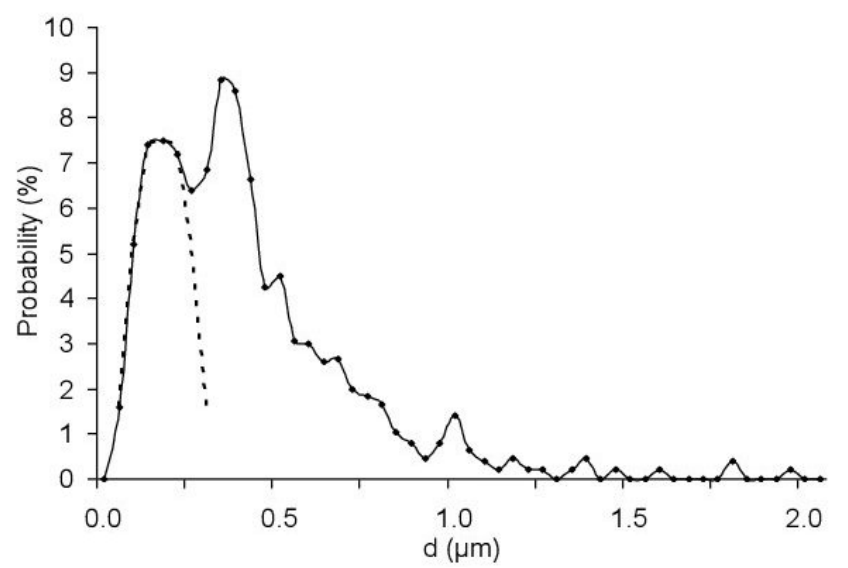

a

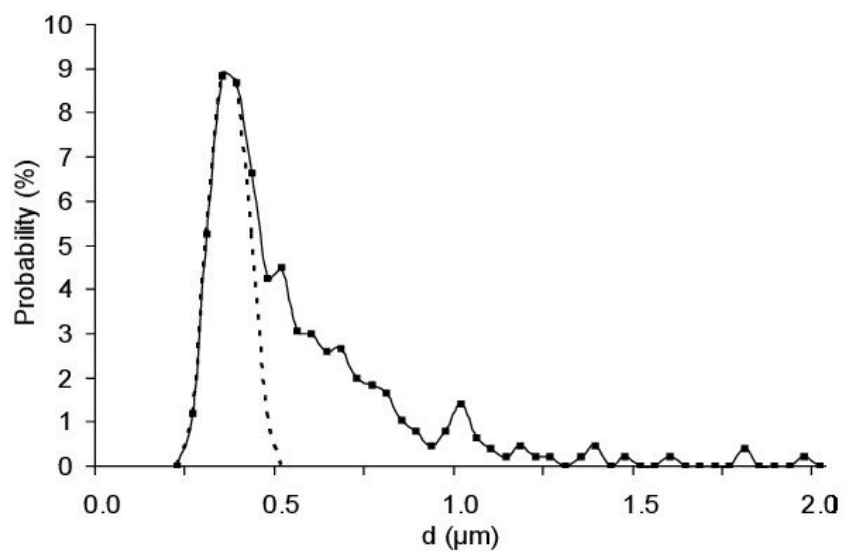

b

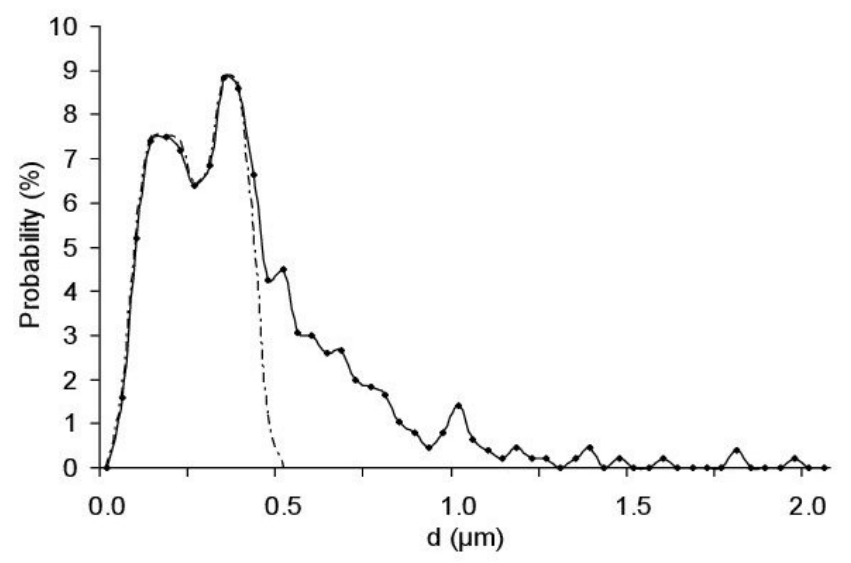

C

Figure 6. Short-cut method of PP nanofibres diameter distribution: (a) the first distribution marked by the short-cut method; (b) the second distribution marked by the short-cut method; and (c) the total distribution marked by the short-cut method.

It is necessary to observe that the distributions obtained according to the short-cut method correspond to the empirical distribution very well (Figs 3 and 6(c)), and this means that this method can be used for dividing the compound distribution into single distributions.

In the next step of our investigation, the criteria for the evaluation of structure quality are proposed. While analysing literature sources, it was observed that the average diameter is used as the main parameter of nanofibre characterisation and according to the changes in average diameter, the authors make conclusions about the influence of the various parameters on a nonwoven structure. For this reason, the authors usually achieved controversial results. However, in the previous work [25] we established that the average value cannot be used alone for an evaluation of web quality, because changes in this value do not necessarily imply changes in the modal value or value of dispersion.

For the average diameter of nanofibres, we propose the use of the modal value of the first distribution, plus the percentage quantity of all the fibres distributed by the first distribution and the diameter ( $\left.d^{\prime}\right)$ of the two modal values of their distribution. These values can be used for comparing various webs composed of nanofibres. A higher percentage quantity means a more unique structure for the web and a less wide of dispersion as well. The diameter $d^{\prime}$ can be calculated using the formula in Equation (1)

$$
d^{\prime}=d_{\text {modal }} \times a+d_{2 \text { modal }} \times b
$$

where $d_{\text {modal }}$ is the first modal value of the entire distribution; $d_{2 \text { modal }}$ is the second modal value of the distribution; $a$ and $b$ are the percentage quantities of the first distribution and second distribution.

These mathematical criteria show the influence of various parameters on the structure of manufactured web and it is possible to compare different distributions when the diameter of nanofibres is distributed differently. 


\section{Conclusions}

- The various distributions of nanofibres are very complex, and the shapes of such distributions are usually very close to a compound one consisting of several normal distributions.

- A compound distribution can be divided into single distributions by utilising the short-cut method presented in this article.

- The modal value and the percentage quantity of the first distribution, along with the diameter $d^{\prime}$ of the two modal values, can be used for the evaluation of a web structure.

\section{Acknowledgements}

The authors acknowledge the contribution of the 7FP 2BFUNTEX and COST Action MP1206.

\section{References}

[1] Mazoochi, T., Hamadanian, M., Ahmadi, M., Jabbari V. (2012). Investigation on the morphological characteristics of nanofiberous membrane as electrospun in the different processing parameters. International Journal of Industrial Chemistry, 3(2), 1-8.

[2] Esfandarani, M. S., Johari, M. S. Producing porous nanofibres. Proceedings of the 2nd international conference NANOCON 2010, p. 1-6, Olomouc, Czech Republic.

[3] Tucker, T., Stanger, J. J., Staiger, M. P., Kofman, K. The history of the science and technology of electrospinning from 1600 to 1995. Proceeding of the International Istanbul Textile Congress 2013, p. 1-7, Istanbul, Turkey, 2013.

[4] Cooley, J. F. Improved methods of and apparatus for electrically separating the relatively volatile liquid component from the component of relatively fixed substances of composite fluids. United Kingdom Patent 6385. 19th May 1900.

[5] Melcher, J. R., Warren, E. P. (1971). Electrohydrodynamics of a current - carrying semi-insulating jet. Journal of Fluid Mechanics, 47, 127-143.

[6] Yener, F., Jirsak, O. Fabrication and optimization of polyvinyl butyral nanofibres produced by roller electrospinning Proceedings of the 12th AUTEX World Textile Conference, p. 251-256, Zadar, Croatia, 2012.

[7] loannis, S., Chronakis. (2005). Novel nanocoposites and nanoceramics based on polymer nanofibers using electrospinning process-Review. Journal of Materials Processing Technology, 167, 283-293.

[8] Mo, X. M., Xu, C. Y., Kotaki, M., Ramakrishna, S. (2004). Electrospun $P(L L A-C L)$ nanofiber: A biomimetric extracellular matrix for smooth muscle cell and endothelial cell proliferation. Biomaterials, 25, 1883-1890.

[9] Danelevičiūtè-Vaišnienè, A., Katunskis, J., Buika, G. (2009). Electrospun PVA nanofibres for gas filtration applications. Fibre \&Textiles in Eastern Europe, 17(6), 4043.

[10] Sambaer, W., Zatloukal, M., Kimmer, D. (2010). The use of novel digital image analysis technique and rheological tools to characterize nanofiber nonwovens. Polymer Testing, 29, 82-94.

[11] Šukytè, J., Adomavičiūtè, E., Milašius, R. (2010) Investigation of the possibility of forming nanofibres with potato starch. Fibres \&Textiles in Eastern Europe, 18(5), 24-27.

[12] Vrieze, S. D., Camp, T. V., Nelvig, A., Hagstrom, B., Westbroek, P., et al. (2009). The effect of temperature and humidity on electrospinning. Journal of Materials Science, 44(5), 1357-1362.

[13] Chowdhury, M., Stylios, G. (2010). Effect of experimental parameters on the morphology of electrospun Nylon 6 fibers. International Journal of Basic \& Applied Sciences, 10(06), 116-131.

[14] Ojha, S., Afshari, M., Kotek, R., Gorga, R. E. (2008). Morphology of electrospun nylon 6 nanofibers as a function of molecular weight and processing parameters. Journal of Applied Polymer Science, 108, 308-319, DOI: 10.1002/ app. 27655.

[15] Biber, E., Gunduz, G., Mavis, B., Colak, U. (2010). Effects of electrospinning process parameters on nanofibers obtained from Nylon 6 and poly 9ethylene-n-butyl acrylatemaleic anhydride) elastomer blends using Johnson SB statistical distribution function. Applied Physics A Materials Science \& Processing, 99, 477-487, DOI: 1007/s003390100-5559-6.

[16] Dosunmu, O. O., Chase, G. G, Kataphinan, W., Reneker, D. H. (2006). Electrospinning of polymer nanofibres from multiple jets on a porous tubular surface. Nanotechnology, 17, 1123-1127.

[17] Aluigi, A., Tonetti, C., Rombaldoni, F., Varesano, A., Vineis, $C$., et al. Methylene blue removal from aqueous solution by keratin nanofibres. Proceedings of the 12th AUTEX World Textile Conference, 287-290, Zadar, Croatia 2012.

[18] Ellison, C. J., Phatak, A., Giles, D. W., Macosko, C. W., Bates, F. S. (2007). Melt blown nanofibres: fiber diameter distributions and onset of fiber breakup. Polymer, 48, 3306-3316.

[19] Casasola, R., Thomas, N. L., Georgiadou, S. Effect of solvent systems on electrospun polymeric fibres: preliminary study on poly lactic acid (PLA). Proceedings of the International Istanbul Textile Congress 2013, p. 1-6, Istanbul, Turkey, (2013).

[20] Tsimpliaraki, A., Zuburtikudis, I., Marras, S. I., Panayiotou, C. Optimizing the nanofibrous structure of non-woven mats of electrospun bio-degradable polymer nanocomposites. Book of Proceedings of International conference Latest Advances in High Tech Textiles and Textile-Based Materials, p. 128-133, Ghent, Belgium, 2009.

[21] Varabhas, J. S., Chase, G.G., Reneker, D. H. (2008). Electrospun nanofibers from a porous hollow tube. Polymer, 49, 4226-4229.

[22] Gu, S., Wu, Q., Ren, J. (2008). Preparation and surface structures of carbon nanofibers produced from electrospun PAN precursors. New Carbon Materials, 23(2), 171-176.

[23] Malašauskiené, J., Milašius, R. (2010). Mathematical analysis of the diameter distribution of electrospun nanofibres. Fibres \&Textiles in Eastern Europe, 18(6), 4548.

[24] Malašauskiené, J., Milašius, R. Short-cut Method of Electrospun Nanofibres Diameter Distribution Estimation. Book of Proceedings of 6th International Textile, Clothing \& Design Conference - Magic World of Textile, p. 522-525, Dubrovnik, Croatia, 2012.

[25] Malašauskiené, J., Milašius, R. (2013). Investigation and estimation of structure of web from electrospun nanofibres. Journal of Nanomaterials, Article ID 416961, DOI: $10.1155 / 2013 / 416961$.

[26] Leaf, G. A. V. Practical Statistics for the Textile Industry: Part I, The Textile Institute, Manchester, 1984. 